\title{
THE EFFECTS OF MOTORTRIGEMINAL DENUCLEA- TION ON RAT MASTICATORY MUSCLES
}

\author{
Tokuichi Hiraiwa \\ Department of Physiology, Faculty of Dentistry, Kyushu University, \\ Fukuoka, 812 Japan
}

\begin{abstract}
The effects of electrical destruction of the trigeminal motor nucleus of rat masticatory muscles were investigated with the aid of histochemical, cytological and physiological experimental procedures. Atrophy of the muscle fibers occurred 5 to 7 days after denucleation. Changes in the histochemical properties were found after denucleation: oxidative enzyme and glycolytic enzyme decreased, and acid phosphatase increased. Myosin ATPase and acetylcholinesterase activity did not, however, change significantly. Ultrastructural study of the muscle after denucleation revealed the progressive loss of contractile materials and changes of sarcoplasmic substructures. Nerve terminals broke up into small fragments and were replaced by Schwann cells. When electrically stimulated, the muscles exhibited a slower rate of rise of contraction and time delay in reaching peak tension. The stimulus frequency to produce tetanic tension decreased. The cessation of spontaneous miniature end plate pontentials occurred abruptly about $30 \mathrm{hr}$ after denucleation and depolarization of the membrane was observed. Extrajunctional acetylcholine supersensitivity appeared 2-3 days after denucleation and reached a maximum value 10 days after denucleation. Membrane resistance, effective resistance, time constant and length constant increased about five days after denucleation. The rate of rise of the action potential was reduced and the action potential became partially insensitive to tetrodotoxin.

It is concluded that the degenerative effects of denucleation of the masticatory muscle after trigeminal motor nucleus destruction are the same as the effects of cutting the motor nerve. Therefore, in preparation of denervated muscle, the relatively simple procedure of denucleation is recommended in lieu of the more difficult cutting of the nerve fibers.
\end{abstract}

In mammalian skeletal muscle, cutting a motor nerve results in a number of characteristic changes in histochemical, cytological and physiological properties.

Received for publication August 1, 1977

平岩徳一 
Histologically, TOWER (1935) observed denervation atrophy and suggested that this was not merely the results of disuse, but was mainly due to the loss of some neural regulation. RomANUL and HogAn (1965) investigated the activities of a number of enzymes in rat skeletal muscle by histochemical methods before and after nerve sectioning and showed that the histochemical differences attributed to the distribution of enzymes among the various types of muscle fibers gradually decreased and tended to disappear after sectioning. Furthermore, study of the biochemical changes in enzymatic activities of glycolysis and oxidative processes in muscle energy metabolism, acetylcholinesterase (AChE), myosin ATPase and the lysosomal enzyme disclosed post-denervation decreases in the activities of all except the lysosomal enzyme which increased after nerve sectioning (GUTH et al., 1964; Hogan et al., 1965; Karpati and Engel, 1968; Gutmann et al., 1972; KRISHNAMOORTHY et al., 1975).

Atrophied denervated fibers showed reduction in mitochondria, the degenerative autolytic process, alteration in the Z-lines, the disposition of filaments, and structural changes of the sarcoplasmic reticulum (SR) (PELlergrino and FranZini, 1963; Muscatello and Patriarca, 1968). Furthermore, Miledi and SLATER (1970) observed degeneration of nerve terminal in the rat diaphragm after phrenic nerve sectioning. They suggested that the degeneration was triggered by a signal which passed from the site of injury to the nerve terminal. In addition to these structural changes, GAUTHIER and DUNN (1973) reported massive accumulations of free ribosomes and a few cisternae of rough-surfaced endoplasmic reticulum following denervation and they, therefore, speculated that this concentration of protein synthetic machinery might correspond to a spread in sensitivity to acetylcholine $(\mathrm{ACh})$ along the surface of the fibers.

Contraction time of muscle is thought to be regulated by motoneurons (ECCLES et al., 1962), and the prolongation of contraction time has been described repeatedly as a characteristic sign of denervation atrophy (LEWIS, 1962, 1972; GUTMANN et al., 1972).

Changes in the electrophysiological properties following denervation have been reported by numerous investigators. Transmission failure occurs abruptly, and is accompanied by cessation of spontaneous miniature end-plate potential (m.e.p.p.) (Miledi and Slater, 1970). Resting membrane potential (RMP) decreases, especially during the earlier stage when there is no alteration of the electrical constants of the muscle membrane (AlbuQuerque and McIsaAC, 1970). In an innervated muscle, ACh produces membrane depolarization only when applied to the end-plate region (DEL CASTILlo and KATZ, 1955). Denervated muscle fiber becomes sensitive to ACh along the entire muscle membrane (AxELSSON and THESLEF, 1959). It is known that tetrodotoxin (TTX) suppresses the action potential of the normally innervated muscle fiber, but the action potential of denervated muscle fiber shows resistance to TTX even at high concentrations which would completely suppress the action potential of innervated muscle fiber (RED- 
FERN and THESLEFF, 1971). Furthermore, in denervated muscle, fibrillatory potentials occur cyclically during denervation (PuRves and SAKMANN, 1974).

In general, mammalian skeletal muscle fibers are classified into three types identified mainly by various histochemical staining methods. With myosin ATPase staining and the duration of contractile properties, two major types (I and II) have been identified (Dubowitz and Pearse, 1960; Engel, 1962). Red and white muscle fibers correspond to type II, and intermediate muscle fibers with type I. In the masticatory muscles, from histochemical results, M. masseter (M. mass.) and $M$. temporalis ( $M$. temp.) were observed to be composed of type II (fast twitch muscle fibers) exclusively; and $M$. digastricus ( $M$. digast.) and $M$. pterygoideus medialis (M. ptery. med.) were composed of type II and type I (slow twitch muscle fiber).

Rat masticatory muscles are innervated by motoneurons from the trigeminal motor nucleus. However, it is difficult to cut the nerve without injury to the muscle due to the anatomical arrangement of the distributed nerve fibers in the masticatory muscle. Therefore, the present investigation was achieved by electrical destruction of the trigeminal motor nucleus, a relatively easy method, technically. The purpose of this research was detailed examination of the effects of denucleation of the motor nucleus on the histochemical, cytological and physiological properties of masticatory muscles since no such studies have been reported. The results are compared to those reporting on nerve sectioning.

\section{METHODS}

Preparation. Female adult W.K.A. rats weighing 200 to $250 \mathrm{~g}$ were used. The animals were anesthetized with pentobarbital sodium $(25 \mathrm{mg} / \mathrm{kg}$, ip). Anesthetized rats were placed in a stereotaxic instrument and the right region of the trigeminal motor nucleus was explored by stimulation with a $0.5 \mathrm{~mm}$ diameter bipolar electrode inserted into the brain stem from the occiput. A bipolar needle electrode was inserted into the right $M$. mass. to detect the EMG unit discharges generated by stimulation of the ipsilateral trigeminal motor nucleus. After orientation of the electrode, the right trigeminal motor nucleus was destroyed by an anodal DC current $(1 \mathrm{~mA}$, about $15 \mathrm{sec})$ applied through a $0.5 \mathrm{~mm}$ diameter unipolar electrode. At intervals of time varying from 1 to 28 days following denucleation, the animals were sacrificed, and the site of destruction was confirmed histologically.

Figure 1 shows a hematoxylin-eosin stained frontal section 7 days after destruction of the right trigeminal motor nucleus. The electrolytic lesion included the entire right trigeminal motor nucleus, but the sensory nucleus (mesencephalic nucleus) remained intact. M. mass., M. temp., M. ptery. med., M. digast. (Venter anterior; $V$. ant.) and $M$. digast. (Venter posterior; $V$. post.) of the masticatory muscles were carefully dissected out from one end of the muscle tissue to the other, 


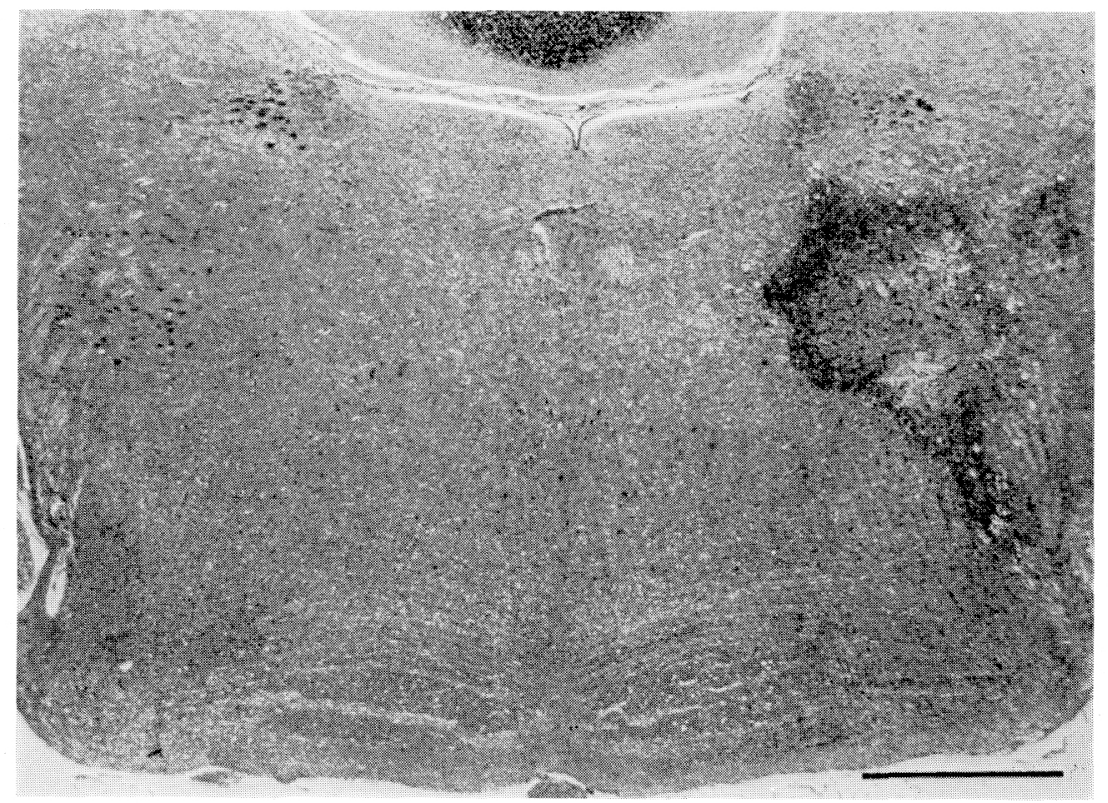

Fig. 1. Hematoxylin-eosin staining of the trigeminal motor nucleus region 7 days after denucleation of the right motor nucleus. $\operatorname{Bar}=1 \mathrm{~mm}$.

including the tendon tissue. After having excised the muscle tissues from the body, the connective tissue was carefully removed under a binocular microscope and placed in Krebs solution at $20-22^{\circ} \mathrm{C}$. In the histochemical study all five masticatory muscles were examined. In the cytological study the $M$. mass., as representative of type II, and M.digast. ( $V$. ant.), as representative of mixed type, were examined. For the electrophysiological study, it is difficult to acquire an intracellular record of type I muscle fiber from $M$. digast. ( $V$. ant .) since these muscle fibers lie in the deeper portions of the muscle. Therefore, only M. mass. was chosen as representative of type II fiber (fast twitch muscle fiber).

Histochemical procedure. M. mass., M. temp., M. ptery. med., M. digast. ( $V$. ant.) and $M$. digast. (V. post.) were removed from both sides at $3,5,7,10,14$, 21 and 28 days after denucleation. From the midpoint of the muscle bellies of the denucleated and control muscles, a $10 \mathrm{~mm}$-thick cylindrical segment was mounted in transverse section so that the denucleated and control muscle of the same animal (right and left side, respectively) were on the same chuck. Freezing was done by immersing the chuck into acetone chilled with dry ice. Cryostat sections of $6 \mu \mathrm{m}$ thick were prepared in a routine manner. The sections were stained by the following histochemical procedures; myosin ATPase by PADYKula and HERMAN (1955), succinate dehydrogenase (SDH) by NACHLAS et al. (1957), acid phosphatase by Gomori (1950), AChE by Koelle and Friedenwald (1949), phosphorylase (PhR) by Takeuchi and Kuriake (1955), and PAS (periacid Schiff method) for 
glycogen by MCManus and Mowry (1960). Sections of a given muscle from the denucleated and control sides of the same animal were stained in the same incubating medium at the same time and mounted together on a slide glass. The stained sections were photographed on reversal film and enlarged using a slide projector to provide sufficient magnification to identify and measure the diameter and percentage of the different fiber types. Muscle fibers were initially classified into three types with SDH and myosin ATPase: red, intermediate and white (MASUDA et al., 1974). However, at a later stage (14 days), since after denucleation other histochemical reactions were markedly reduced and it became difficult to identify the 3 types, only myosin ATPase was used to differentiate 2 types, type I (intermediate) and type II (red and white). Measurements of the diameter and percentage of the different fiber types were made in 4 animals from each of the 7 groups. The differences between the mean values of the denucleated and normal animals were analyzed by the $t$ test for statistical significance.

Electron microscope procedure. Eight rats were sacrificed for electron microscopic study at 3, 7, 10, 14 days after denucleation. $M$. digast. (V. ant.) and $M$. mass. were fixed for $2 \mathrm{hr}$ in $3 \%$ glutaraldehyde containing $2 \mathrm{mM} \mathrm{CaCl}_{2}$ in $0.1 \mathrm{M}$ cacodylate buffer ( $\mathrm{pH}$ 7.3). During the fixation, the muscles were cut into small pieces. After aldehyde fixation the specimens were washed for $30 \mathrm{~min}$ in $0.1 \mathrm{M}$ cacodylate buffer containing $7 \%$ sucrose, and post-fixed for $2 \mathrm{hr}$ in $1 \%$ osmium tetroxide containing $2 \mathrm{mM} \mathrm{CaCl}_{2}$ in $0.1 \mathrm{M}$ cacodylate buffer. They were then dehydrated and embedded in Epon. Sections were cut on a MT-1 (Sorvall) ultramicrotome, stained with uranyl-acetate and lead, and then examined with an HS-8 (Hitachi) electron microscope.

Mechanogram procedure. In order to observe the mechanical properties induced by electrical stimulation, $M$. mass. were isolated from 24 rats at 5, 7, 10 and 14 days after denucleation. To stimulate the muscle electrically, a multi-electrode assembly was placed parallel to the tissue. The length of the electrode was $20 \mathrm{~mm}$, which was longer than the muscle preparation, and the distance between electrodes was $4 \mathrm{~mm}$. The muscle preparations of the control side and denervated side were fixed simultaneously in the bath in vivo in length; and the isometric tensions were recorded by strain gauge.

Electrophysiological procedure. M. mass. was isolated at 1, 2, 3, 5, 7, 10, 14, 21 days after denucleation. Electrophysiological observations were made on the following properties; spontaneous m.e.p.p., extrajunctional ACh sensitivity, RMP, passive electrical properties of the membrane, action potential generation and sensitivity to TTX. Records were made only from surface fibers of the posterior portions in M. mass. They were made in a conventional manner with a glass micropipette filled with $3 \mathrm{M} \mathrm{KCl}$, having a resistance of 10 to $30 \mathrm{M} \Omega$. The characteristic constants of the membrane were calculated by applying the cable theory of Hodgkin and Rushton (1946), and FALK and FATT (1964). In order to investigate the various membrane constants, two microelectrodes were inserted at various 
distances along a single fiber, one for passing current and the other for recording. To determine the membrane time constant $\left(\tau_{m}\right)$, the distance between electrodes was kept within about $10 \mu \mathrm{m}$.

ACh (4 M) was applied iontophoretically to measure the sensitivity of the extrajunctional membrane at $1 \mathrm{~mm}$ distance from the end-plate region. Spontaneous diffusion of ACh was controlled by an adjustable inward current as described by KRnJević and Miledi (1958). ACh sensitivity was expressed as the amplitude of the transient membrane depolarization per unit charge passed through the $\mathrm{ACh}$ pipette; i.e., $\mathrm{mV}$ depolarization per nano coulomb $(\mathrm{nC})$. At each recording the ACh pipette position was carefully adjusted to give the sharpest potential.

Action potential generation was done by two intracellular microelectrodes, as described previously, within the distance of about $10 \mu \mathrm{m}$ along a single fiber. To compare the effect of TTX on action potential between denucleated and innervated muscle fibers, the membrane of the denucleated fiber was hyperpolarized to the level of the innervated fiber by an anodal D. C. current since the resting membrane potential of the denucleated fiber was lower than that of innervated fiber. Experiments were carried out at $34^{\circ} \mathrm{C}$.

Solution and drugs. The solution used in physiological experiments was a modified Krebs solution of the following composition (mM); $\mathrm{Na}^{+} 137.4 ; \mathrm{K}^{+}$ $5.9 ; \mathrm{Mg}^{++} 1.2 ; \mathrm{Ca}^{++} 2.5 ; \mathrm{Cl}^{-} 134.0 ; \mathrm{HCO}_{3}^{-} 15.5 ; \mathrm{H}_{2} \mathrm{PO}_{4}^{-} 1.2 ;$ glucose 11.5 ; equilibrating with $97 \% \mathrm{O}_{2}+3 \% \mathrm{CO}_{2} . \mathrm{pH}$ of the solution was adjusted to 7.2. TTX (M. W. 319.3; Sigma Co.) was prepared as needed from a refrigerated stock solution $\left(10^{-5} \mathrm{~g} / \mathrm{ml}\right)$ in deionized double-distilled water.

\section{RESULTS}

\section{Histochemical properties after denucleation}

With the myosin ATPase and SDH staining methods, the innervated muscle fibers could be classified into three different fiber types; red, white and intermediate. With myosin ATPase staining, red and white muscle fibers (type II) were stained darkly and intermediate muscle fibers (type I) lightly. With the SDH staining method, red and intermediate muscle fibers were stained intensely or moderately, and white muscle fibers were stained weakly. Table 1 shows the classification of fiber types of masticatory muscles and the changes of composition of different types after denucleation. M. digast. (V.ant.), M. digast. (V.post.) and M. ptery. med. consisted of three different fiber types; and $M$. mass. and $M$. temp. included red and white fiber types. The fiber type ratios of denucleated muscle (the muscle on the denucleated side) and control muscle (the muscles on the contralateral side) were statistically not significantly different from those of normal muscle (the muscle of normal animals) for up to two weeks after denucleation $(p>0.05)$. At three weeks after denucleation, it became difficult to differenciate red muscle fibers from white muscle fibers due to the reduction in SDH activity in red muscle fiber. 
Table 1. Percentage of each fiber type in innervated and denucleated masticatory muscles as a function of days after denucleation.

\begin{tabular}{|c|c|c|c|c|c|c|c|}
\hline & \multirow{2}{*}{ Days } & \multicolumn{2}{|c|}{ Red } & \multicolumn{2}{|c|}{ White } & \multicolumn{2}{|c|}{ Intermediate } \\
\hline$\because$ & & D & $\mathrm{C}$ & $\mathrm{D}$ & $\mathrm{C}$ & $\mathrm{D}$ & $\mathrm{C}$ \\
\hline \multirow[t]{5}{*}{ M. digast. (V.ant. $)$} & 0 & \multicolumn{2}{|c|}{69.7} & \multicolumn{2}{|c|}{23.0} & \multicolumn{2}{|c|}{7.3} \\
\hline & 7 & 70.0 & 69.7 & 22.8 & 22.5 & 7.2 & 7.8 \\
\hline & 14 & 71.2 & 68.8 & 21.1 & 23.8 & 7.7 & 7.4 \\
\hline & 21 & (91.9) & 70.1 & & 22.3 & 8.1 & 7.6 \\
\hline & 28 & $(93.0)$ & 70.5 & & 21.7 & 7.0 & 7.8 \\
\hline \multirow[t]{5}{*}{ M. digast. $(V$. post.$)$} & 0 & \multicolumn{2}{|c|}{68.9} & \multicolumn{2}{|c|}{20.5} & \multicolumn{2}{|c|}{10.6} \\
\hline & 7 & 67.0 & 70.7 & 22.3 & 18.6 & 10.7 & 10.7 \\
\hline & 14 & 68.5 & 67.4 & 20.1 & 21.8 & 11.4 & 10.8 \\
\hline & 21 & 69.1 & 68.3 & 21.2 & 21.2 & 9.7 & 10.5 \\
\hline & 28 & 68.0 & 67.6 & 20.7 & 22.1 & 11.3 & 10.3 \\
\hline \multirow[t]{5}{*}{ M. ptery. med. } & 0 & \multicolumn{2}{|c|}{59.8} & \multicolumn{2}{|c|}{35.4} & \multicolumn{2}{|c|}{4.8} \\
\hline & 7 & 61.7 & 59.3 & 33.0 & 35.8 & 5.3 & 4.9 \\
\hline & 14 & 53.5 & 58.4 & 42.0 & 36.6 & 4.5 & 5.0 \\
\hline & 21 & $(95.8)$ & 60.1 & & 36.0 & 4.2 & 3.9 \\
\hline & 28 & $(95.2)$ & 60.4 & & 35.5 & 4.8 & 4.1 \\
\hline \multirow[t]{3}{*}{ M. mass. } & 0 & \multicolumn{2}{|c|}{49.9} & \multicolumn{2}{|c|}{50.1} & & \\
\hline & 7 & 50.8 & 53.4 & 49.2 & 46.6 & & \\
\hline & 14 & 46.5 & 54.7 & 53.5 & 45.3 & & \\
\hline \multirow[t]{3}{*}{ M. temp. } & 0 & \multicolumn{2}{|c|}{46.5} & \multicolumn{2}{|c|}{53.5} & & \\
\hline & 7 & 50.2 & 47.8 & 49.8 & 52.2 & & \\
\hline & 14 & 42.3 & 47.2 & 57.7 & 52.8 & & \\
\hline
\end{tabular}

After 21 days of denucleation only two types (intermediate and others) can be identified, since at that time it becomes difficult to differentiate red and white muscle fibers. D, denucleated; C, control muscle.

Intermediate muscle fibers, however, were clearly distinguishable from other fiber types with myosin ATPase activity even after four weeks of denucleation. The fiber type ratio of intermediate muscle fiber (type I) to other muscle fibers (type II) did not change significantly.

Table 2 shows the changes in the fiber diameter of the masticatory muscle after denucleation. In all masticatory muscles excepting $M$. digast. ( $V$. post.), innervated by facial nerve, atrophy was significant at 5 to 7 days following denucleation. On the other hand, the control side muscles showed only a slight compensatory hypertrophy of the muscle fibers.

Following denucleation, the activity of SDH in muscle mitochondria decreased progressively in red and intermediate muscle fibers, while in white muscle fibers it remained unchanged. Figure 2A shows SDH stained sections of denucleated and control muscle fibers of $M$. mass. at three weeks after denucleation. The most marked decrease in activity of the denucleated muscles occurred in red muscle fibers which normally showed high content, and little or no change was observed in white muscle fibers which originally showed low content. In normal red muscle 


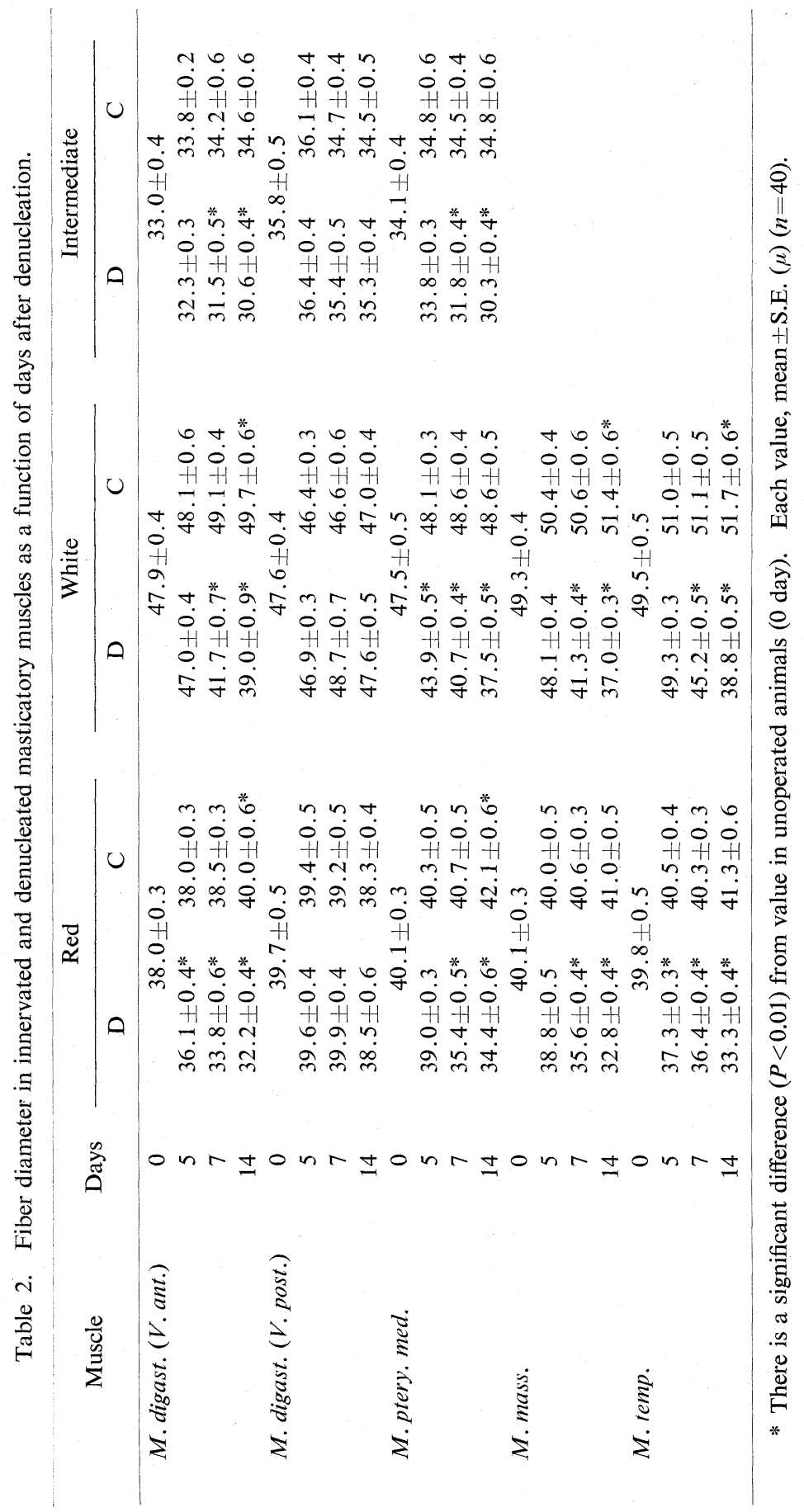




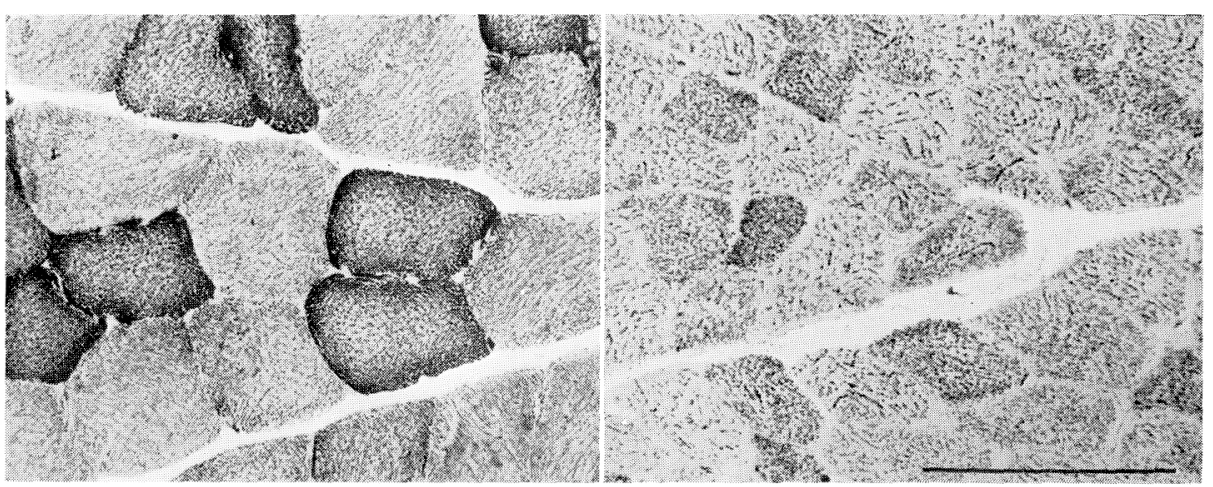

A
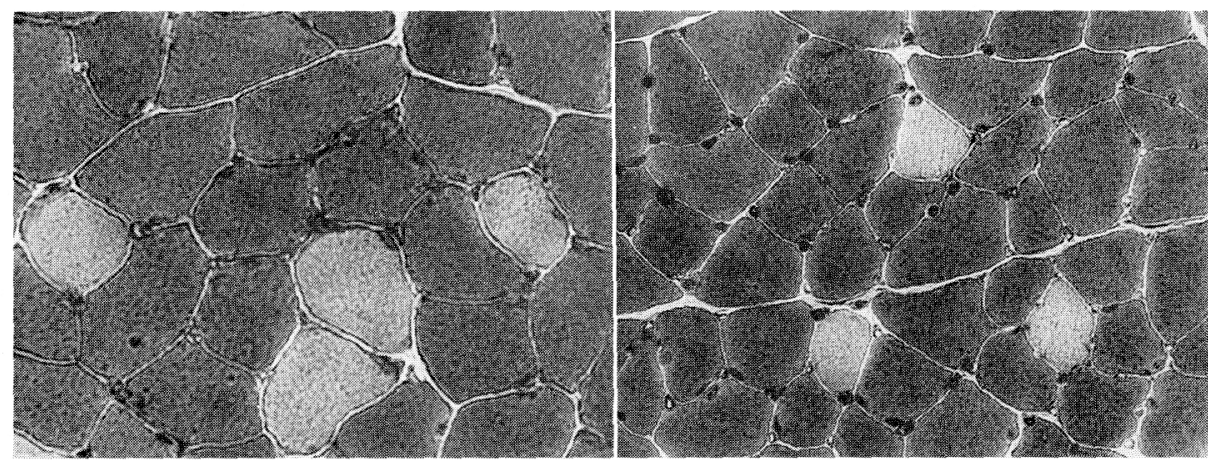

B

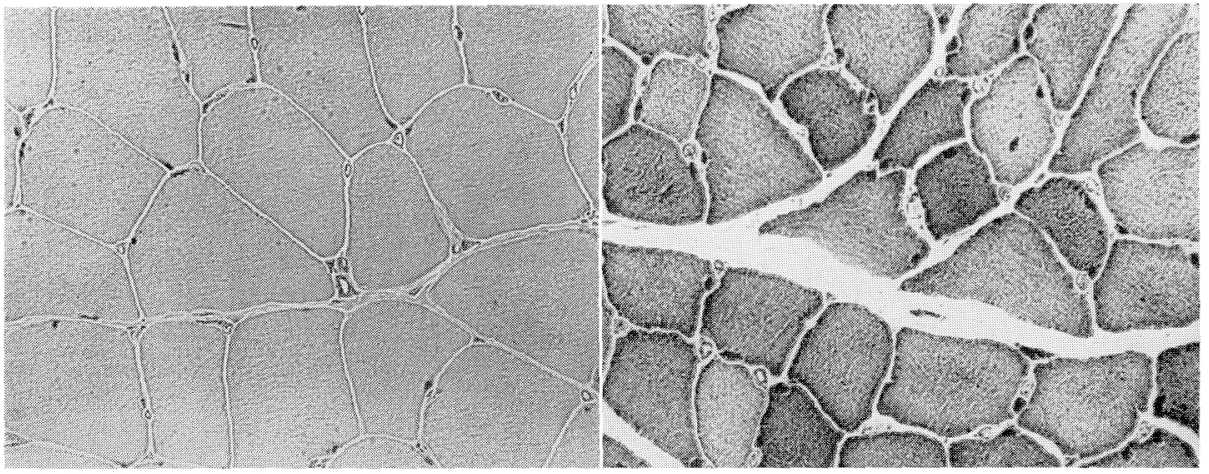

$\mathrm{C}$

Fig. 2. Various stainings 3 weeks after denucleation. A, succinate dehydrogenase staining of $M$. mass.; B, myosin ATPase staining of $M$. digast. (Venter anterior); C, acid phosphatase staining of $M$. temp. Left, control; right, denucleated muscle. Bar $=100 \mu \mathrm{m}$. 
fibers, the activity of SDH was located under the sarcolemma, around the sarcolemmal nuclei and between the myofibrils. The sarcolemmal concentration was very prominent. At 10 days after denucleation the sarcolemmal concentration disappeared almost completely in red muscle fibers of denucleated muscles, and activity between the myofibrils decreased. One month after denucleation, the sarcolemmal concentration was further decreased and differentiation from white muscle fibers became extremely difficult.

Histochemical reactions of PhR and PAS staining, which indicated the respective distributions of glycolytic enzyme and glycogen, also decreased following denucleation. PhR and glycogen were normally high in red and white muscle fibers (type II) and low in intermediate muscle fibers (type I). Reduction of these was seen mainly in red and white muscle fiber in the denucleated muscles. The reduction in PhR occurred at the same time as that of SDH, but the glycogen contents decreased more slowly than other enzymes.

Figure 2B shows myosin ATPase of the control and denucleated muscles at 3 weeks after denucleation in $M$. digast. $(V$. ant.). In spite of the reduction in the fiber diameter, activity of myosin ATPase was not affected. Acid ATPase, which was acid-preincubated myosin ATPase and showed negative histochemical profiles (SAMAHA et al., 1970), was not affected by denucleation.

Normally slight acid phosphatase activity increased very rapidly after denucleation (Fig. 2C). It appeared at 3 to 5 days after denucleation, earlier than the decrease in SDH and PhR. At an earlier stage of denucleation the activity of this enzyme was localized in the peripheral region of muscle fiber, but later it appeared evenly throughout the whole muscle fiber. The changes in these enzymes and glycogen were seen only in the denucleated muscle fibers. M. digast. (V.post.) never showed any change in histochemical profiles; it was innervated by facial nerve.

AChE distribution of $M$. digast. $(V$. ant.), studied two weeks after denucleation by the Koelle's method, is shown in Fig. 3. AChE reaction was slightly decreased by denucleation. This enzyme was localized at the end-plate region and the staining area is thought to give the actual size of the end-plate. Denucleation never changed the end-plate distribution of approximately $1.2 \mathrm{~mm}$ width (Fig. 3A and B). The magnified end-plate structures in the denucleated and control muscles is shown in Fig. 3C. The size and structure of these end-plate, considered to be indicative of white muscle fiber, were not changed by denucleation.

\section{Morphological changes after denucleation}

After denucleation, the usual morphological criteria for identifying muscle fiber types are lost except for the width of the Z-line. The width of the Z-line,

Fig. 3. Acetylcholinesterase staining of $M$. digast. (Venter anterior) 2 weeks after denucleation. Left, control; right, denucleated muscle. A, low; B, medium; $\mathrm{C}$, high magnification. Bars: A, $1 \mathrm{~mm}$; B, $100 \mu \mathrm{m} ; \mathrm{C}, 20 \mu \mathrm{m}$. 
A
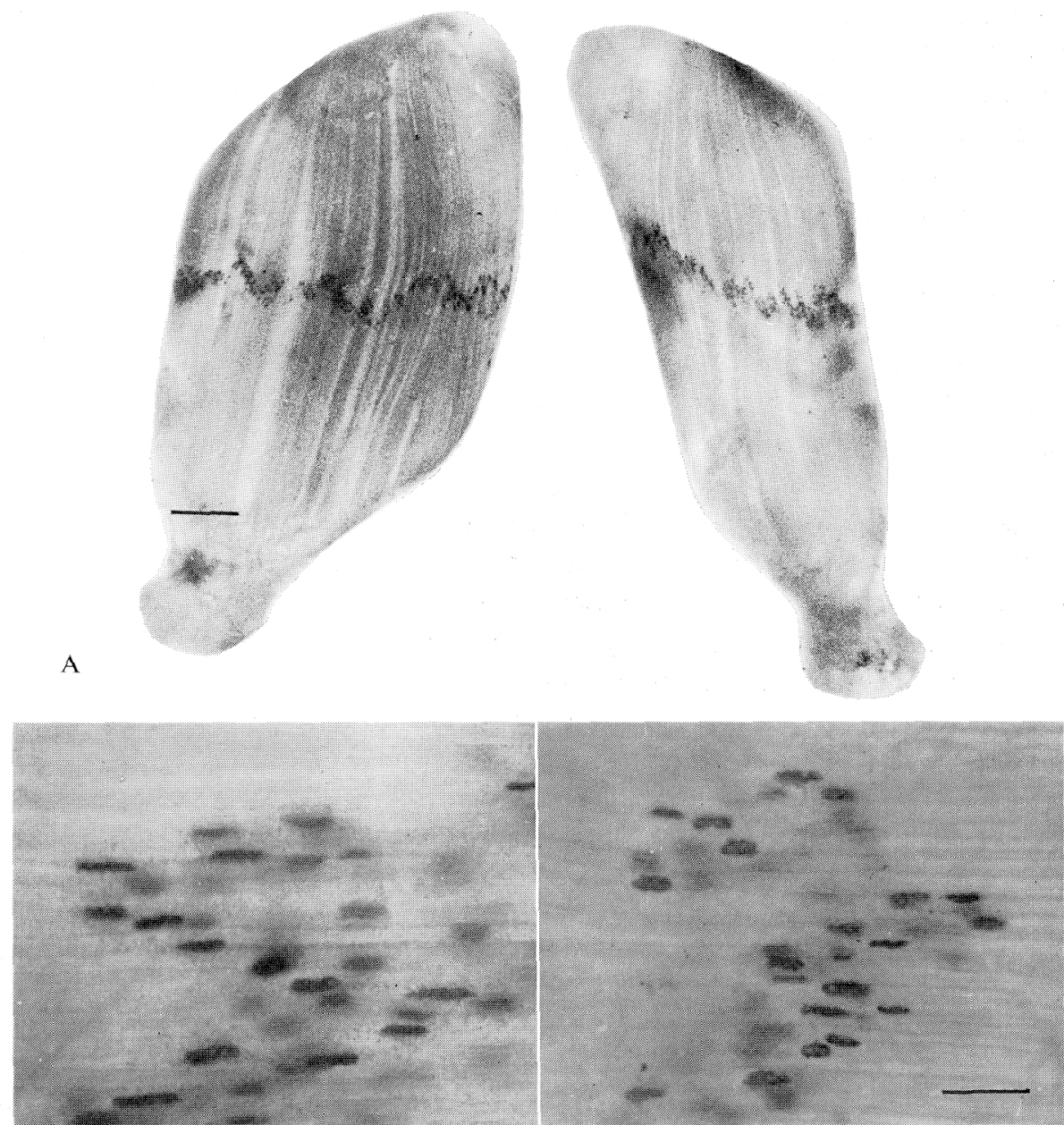

B

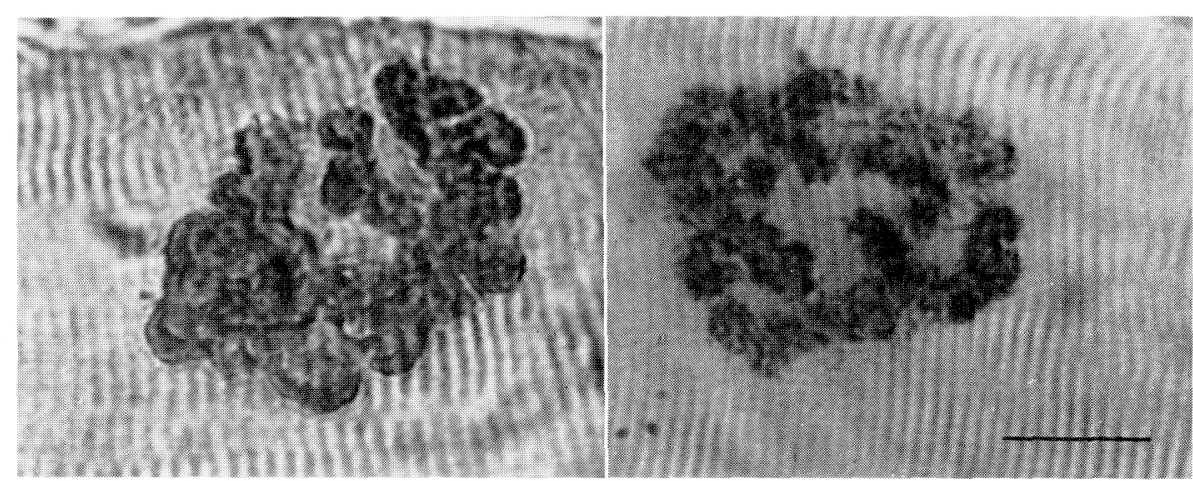

C

Fig. 3 
therefore, is a valuable ultrastructural criterion for identification of normal and denucleated muscle (GAUTHIER, 1969). The rat red muscle fiber had the highest mitochondrial content and the widest Z-line, while the white muscle fiber had the lowest mitochondrial content and the narrowest $Z$-line, about half as wide as that of red muscle fiber. Intermediate muscle fiber was intermediate in both respects.

After denucleation, the first characteristic changes were observed in the endplate. At three days after denucleation it was difficult to detect any change of morphological structure except for the nerve ending. The mitochondria of the degenerating nerve endings acquired a spherical shape. The cristae of these mitochondria were sometimes disorganized and broken up. Synaptic vesicles showed dense clumping, and Schwann cells surrounded the nerve terminal and appeared in the synaptic cleft. Figure 4 shows a nerve terminal in control (contralateral muscle) and denucleated $M$. mass. three days after lesion. In the denucleated muscle, the contests of the axoplasm are disrupted and the nerve terminal broken up into small fragments. Schwann cells appear to extend into the synaptic cleft, to surround fragments of the nerve terminal, and consequently to replace the axon at the end-plate.

As seen in histochemical study it was also possible to detect disarrangement or disappearance of the contractile material, the reduction of mitochondria, a swelling-like transformation of the SR, and disarrangement of the Z-lines at the periphery of the fiber area after 5-7 days. Occasionally, the sarcolemma, normally in contact with the fibrils, showed an irregular wavy surface. Inside many fibers at this stage, the fibrils were partly still preserved, but small lysosomes existed between the fibrils.

From 10 days to 2 weeks after denucleation, a distinct reduction in the number of fibrils took place, especially in red and white muscle fiber. The reduction was accompanied by the disorganization of contractile material and widening of the sarcoplasmic space. Z-lines lost their straight pattern across the fibrils, and became bent. Mitochondria decreased, mainly in the subsarcolemmal region of red muscle fiber and inside the fibrils. The reduction of mitochondria was detected in all three muscle fiber types, although no disappearance of mitochondria was seen. Moreover, the cristae of mitochondria became less distinct. SR underwent a swellinglike transformation. Figure 5A, B and $\mathrm{C}$ show red, intermediate and white muscle fibers, respectively at 10 days after denucleation in $M$. digast. ( $V$. ant.); and Fig. 6 shows SR of red muscle fiber in $M$. digast. ( $V$. ant.) at 10 days after denucleation.

Structural deformation was detected in denucleated muscle fiber. In addition, there was a large number of rough-surfaced endoplasmic reticula and ribosomes in the subsarcolemmal region. These changes were not seen in contralateral muscles except for a slight increase in mitochondria compared with the unoperated muscle.

\section{Changes in membrane and contractile properties after denucleation}

Contraction. Mechanical responses in M. mass. could be evoked by electrical 


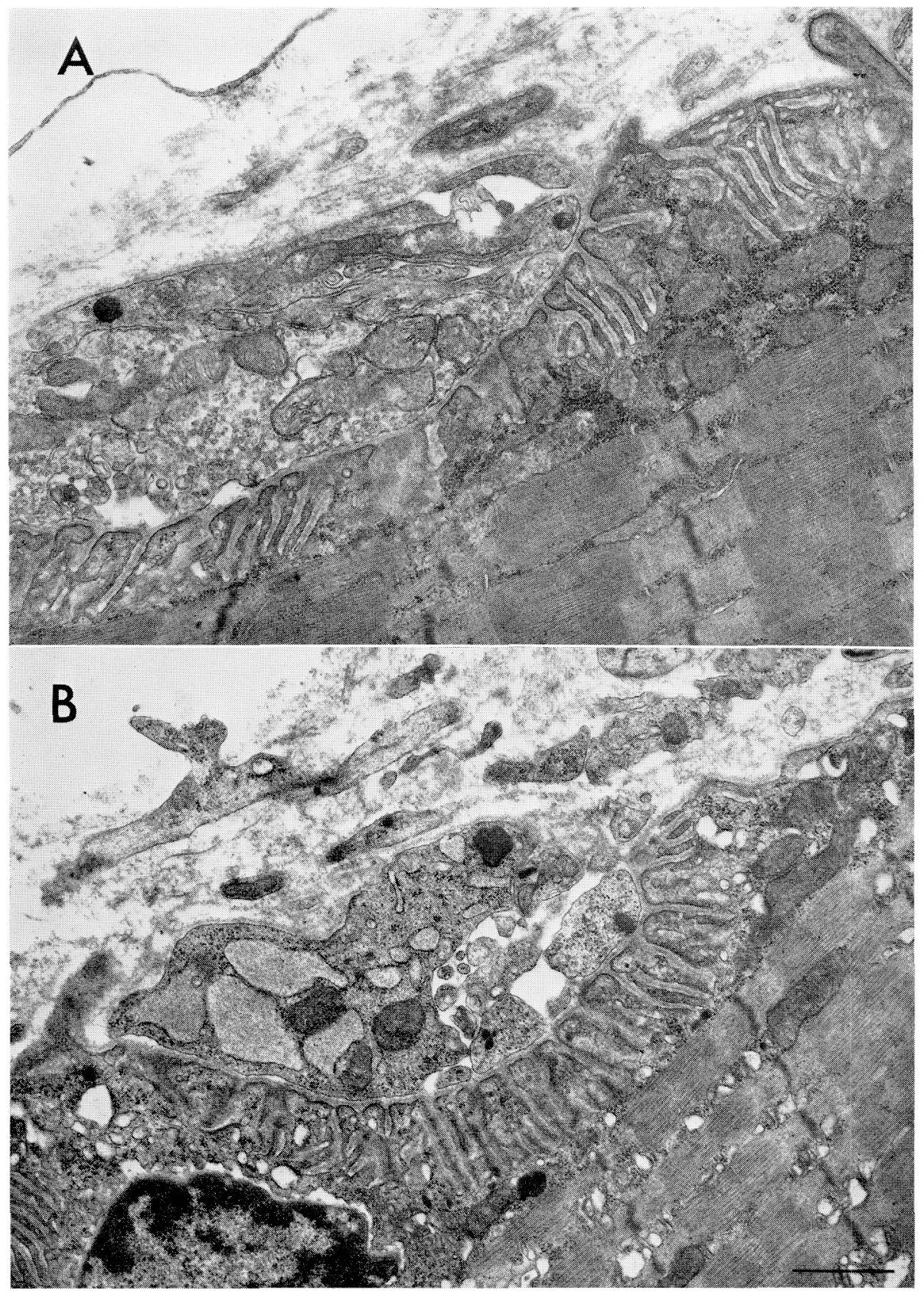

Fig. 4. Electron micrograph of a neuromuscular junction in $M$. mass. 3 days after denucleation. A, control; B, denucleated muscle. Bar $=1 \mu \mathrm{m}$. 


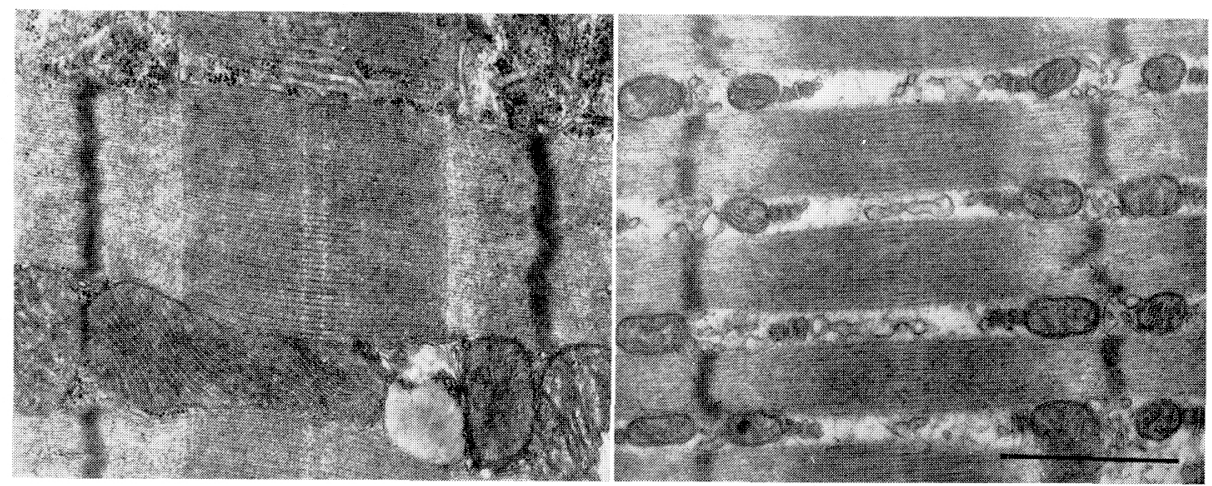

A
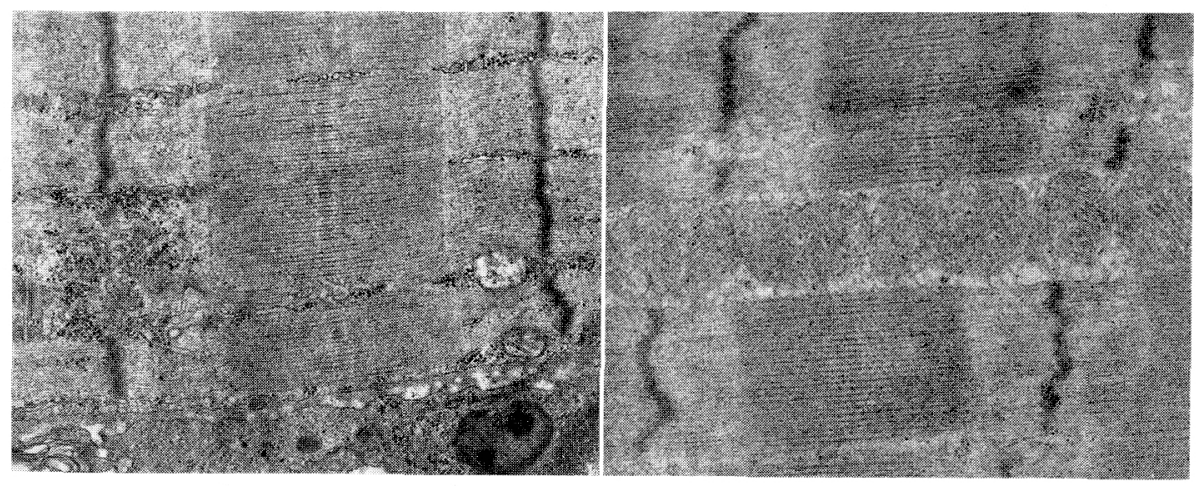

B
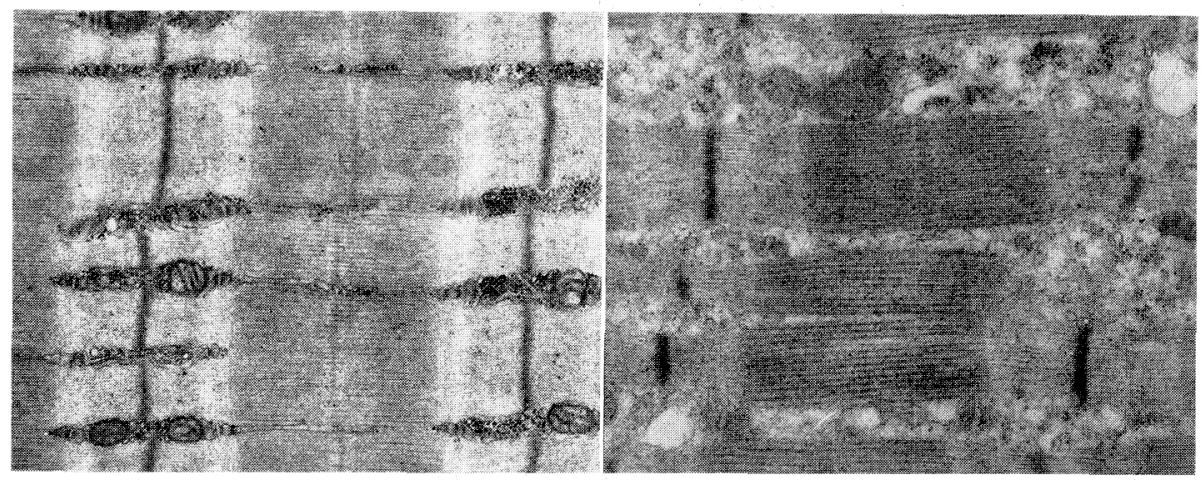

C

Fig. 5. Ultrastructure of 3 muscle fiber types in $M$. digast. (Venter anterior) 10 days after denucleation. Left, control; right, denucleated muscle. A, red muscle fiber; B. intermediate muscle fiber; $\mathrm{C}$, white muscle fiber. $\mathrm{Bar}=1 \mu \mathrm{m}$. 




Fig. 6. Distribution of sarcoplasmic reticulum of red muscle fiber in $M$. digast. (Venter anterior) 10 days after denucleation. A, control; B, denucleated muscle. Bar $=1 \mu \mathrm{m}$. 
stimulation. M. mass. were chosen as representative of the muscles composed of fast-twitch muscle fibers. $M$. mass. developed twitch tension in response to 0.5 msec pulse stimulation. Typical isometric twitch tension curves are illustrated in Fig. 7. In five-day denucleated muscles, the contraction and relaxation times were not significantly different from normal. But muscles denucleated for 14 days were slow to reach peak tension. The time to reach peak tension in control $M$. mass. was $15.2 \pm 0.9 \mathrm{msec}$ (mean \pm S.E.); and in 14 days denucleated muscle, after nerve destruction, was $24.1 \pm 1.7 \mathrm{msec}(n=4)$.

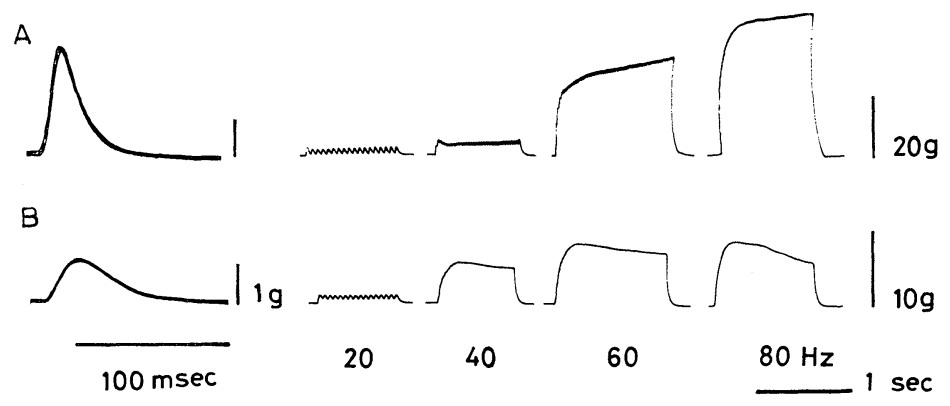

Fig. 7. Effects of various stimulus frequencies on the mechanical responses in M. mass. 14 days after denucleation. A, control; B, denucleated muscle.

The effect of various stimulus frequencies $(1,20,40,60,80 \mathrm{~Hz})$ on mechanical response before and 14 days after denucleation is illustrated in Fig. 7. In the control the mechanical responses began to fuse at about $40 \mathrm{~Hz}$ and showed tetanus at $80 \mathrm{~Hz}$. However, after 14 days of denucleation, it began to show fusion at lower rates, about $30 \mathrm{~Hz}$, and evoked tetanus at about $60 \mathrm{~Hz}$. The amplitude ratio of maximum tetanic tension to twitch tension was $9.8 \pm 1.9(n=4)$ in muscle denucleated for 14 days and $15.6 \pm 2.4(n=4)$ in controls.

Spontaneous transmitter release and ACh sensitivity. During the first $24 \mathrm{hr}$ after denucleation, all muscle fibers of $M$. mass. investigated showed spontaneous transmitter release. Throughout the next $12 \mathrm{hr}$ the number of muscle fibers showing m.e.p.p. generation diminished, and at about $38 \mathrm{hr}$ no generation of spontaneous m.e.p.p. activity was seen (Fig. 8 and left curve of Fig. 9). In most fibers studied prior to cessation of the spontaneous transmitter release, the frequency of m.e.p.p. decreased by a factor of 5 to 10 at about $32 \mathrm{hr}$ after denucleation; but the amplitude, rate of rise and duration of m.e.p.p. were similar to the values obtained in innervated muscle fibers (Fig. 8).

The ACh sensitive area of the innervated M. mass. was found only at the endplate region (about $300 \mathrm{mV} / \mathrm{nC}$ ). When the $\mathrm{ACh}$ pipette was moved more than $500 \mu \mathrm{m}$ away from the end-plate region, the sensitivity was reduced to below $0.01 \mathrm{mV} / \mathrm{nC}$. The right curve in Fig. 9 shows ACh sensitivity at the extrajunc- 

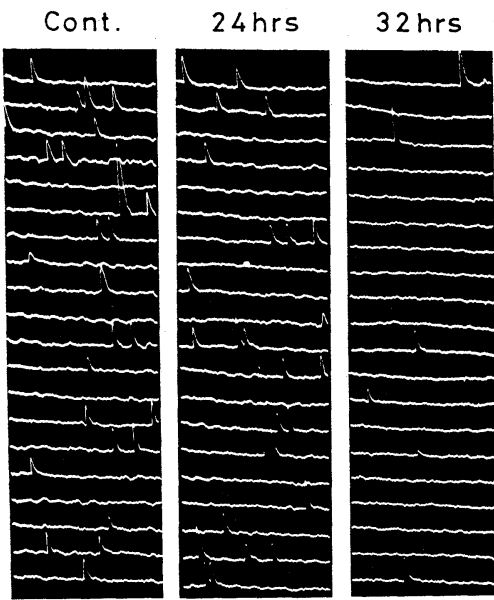

$40 \mathrm{hrs}$

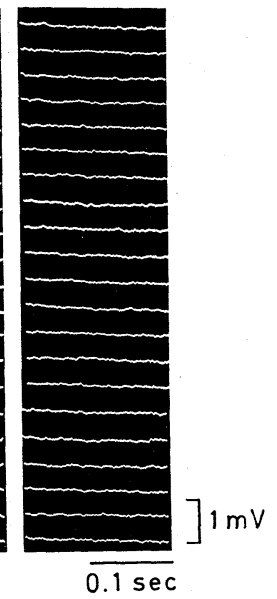

Fig. 8. Spontaneous transmitter release observed in control M. mass. and denucleated $M$. mass. $24 \mathrm{hr}, 32 \mathrm{hr}$ and $40 \mathrm{hr}$ after denucleation.

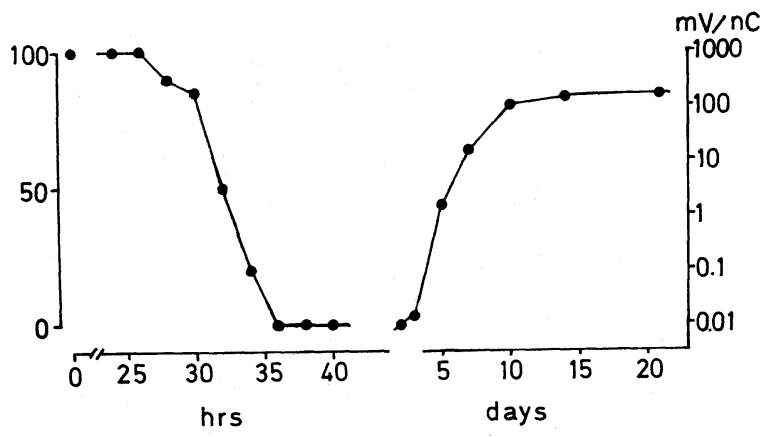

Fig. 9. Time course of m.e.p.p. failure (left) and the extrajunctional ACh sensitivity (right) in $M$. mass. after denucleation. Abscissa, time after operation. Left: ordinate, percentage of impalements in which m.e.p.p.s were observed; each point represents pooled results from 150 to 200 impalements from several muscles. Right: ordinate, $\log \mathrm{ACh}$ sensitivity in $\mathrm{mV} / \mathrm{nC}$; each point represents the $\mathrm{ACh}$ sensitivity at the region 1 $\mathrm{mm}$ away from nerve terminal tested by iontophoretic application of $\mathrm{ACh}$.

tional region ( $1 \mathrm{~mm}$ away from nerve terminal) measured at various intervals after denucleation. Increase in ACh sensitivity at the extrajunctional region appeared about 2-3 days after denucleation and reached a steady level about 14 days after denucleation. For example, the mean values at 3, 5, 7 and 14 days after denucleation were $0.02,2.32,24.3,99.1$ and $234 \mathrm{mV} / \mathrm{nC}$, respectively $(n=20)$ at $1 \mathrm{~mm}$ distance from the end-plate region.

Resting membrane potential, action potential and passive properties of the mem- 
brane. The mean ( \pm S.E.) RMP of the surface fibers of the innervated $M$. mass. was $-81.0 \pm 0.1 \mathrm{mV}(n=200)$. The changes in RMP of the denucleated M. mass. followed. At 1, 3, 5, 7, 10 and 14 days after denucleation the RMP decreased to $-81.1 \pm 0.4 \mathrm{mV}, \quad-75.6 \pm 0.4 \mathrm{mV},-72.2 \pm 0.3 \mathrm{mV},-68.4 \pm 0.3 \mathrm{mV},-65.3 \pm$ $0.4 \mathrm{mV}$ and $-66.3 \pm 0.5 \mathrm{mV}$, respectively $(n=40)$. After 14 days of denucleation there was no further change in RMP.

The various characteristic constants of the membrane were obtained from analysis of the electrotonic potentials elicited by the square pulse. The space constant $(\lambda)$ was obtained from the relationship between the amplitude of the ele-

Table 3. Various characteristic constants of the membrane in innervated and denucleated $M$. mass.

\begin{tabular}{crcccccc}
\hline Days & $n$ & $\begin{array}{c}d \\
(\mu)\end{array}$ & $\begin{array}{c}R_{i n} \\
(\mathrm{M} \Omega)\end{array}$ & $\begin{array}{c}R_{m} \\
\left(\Omega \mathrm{cm}^{2}\right)\end{array}$ & $\begin{array}{c}\tau_{m} \\
(\mathrm{msec})\end{array}$ & $\begin{array}{c}C_{m} \\
\left(\mu \mathrm{F} / \mathrm{cm}^{2}\right)\end{array}$ & $\begin{array}{c}\lambda \\
(\mathrm{mm})\end{array}$ \\
\hline 0 & 15 & $39.7 \pm 0.5$ & $0.63 \pm 0.02$ & $930 \pm 33$ & $2.3 \pm 0.1$ & $2.6 \pm 0.1$ & $0.59 \pm 0.02$ \\
2 & 10 & $39.8 \pm 0.8$ & $0.63 \pm 0.03$ & $940 \pm 61$ & $2.5 \pm 0.2$ & $2.6 \pm 0.1$ & $0.59 \pm 0.02$ \\
3 & 10 & $39.5 \pm 0.9$ & $0.69 \pm 0.02$ & $1060 \pm 46$ & $2.5 \pm 0.1$ & $2.5 \pm 0.1$ & $0.61 \pm 0.02$ \\
5 & 13 & $38.8 \pm 0.6$ & $0.73 \pm 0.02$ & $1160 \pm 36$ & $3.2 \pm 0.1$ & $2.8 \pm 0.1$ & $0.65 \pm 0.02$ \\
7 & 9 & $35.4 \pm 0.9$ & $0.84 \pm 0.02$ & $1350 \pm 59$ & $3.7 \pm 0.1$ & $2.7 \pm 0.1$ & $0.72 \pm 0.02$ \\
10 & 10 & $33.9 \pm 0.9$ & $0.95 \pm 0.04$ & $1490 \pm 67$ & $4.4 \pm 0.1$ & $3.0 \pm 0.1$ & $0.72 \pm 0.01$ \\
14 & 8 & $31.9 \pm 1.0$ & $1.01 \pm 0.03$ & $1470 \pm 57$ & $4.3 \pm 0.1$ & $3.0 \pm 0.1$ & $0.73 \pm 0.01$ \\
\hline
\end{tabular}

$d$ : fiber diameter. See text for other descriptions. Each value, mean \pm S.E.

ctrotonic potential plotted on a logarithmic scale and the distance from the partition electrode. The input resistance $\left(R_{i n}\right)$ was calculated from the current-voltage relation at steady state of electrotonic potential where distance is zero. From these two values, the transverse $\left(r_{m}\right)$ and internal longitudinal $\left(r_{i}\right)$ resistances were calculated as follows; $r_{m}=2 R_{i n} \cdot \lambda$ and $r_{i}=2 R_{i n} / \lambda$. The membrane resistance $\left(R_{m}\right)$ per unit area and the specific resistance of myoplasm $\left(R_{i}\right)$ were obtained from the equation, $R_{m}=2 \pi \rho r_{m}$ and $R_{i}=\pi \rho^{2} r_{i}$ ( $\rho$; fiber radius). The time constant $\tau_{m}$ ) could be measured by inserting two micro-electrodes (for stimulating and recording) in the same muscle fiber, within $10 \mu \mathrm{m}$ of each other. The membrane capacitance $\left(C_{m}\right)$ per unit area was derived from $C_{m}=\tau_{m} / R_{m}$. Table 3 shows the values obtained from the innervated muscles and 3, 5, 7, 10 and 14 days after denucleation. The values obtained up to 3 days after denucleation were not significantly different from those of innervated muscle, but after 5 days significant changes occurred. For example, at 10 days after denucleation the values of the input resistance, membrane resistance, time constant, membrane capacitance and space constant were $0.95 \pm 0.04 \mathrm{M} \Omega, 1490 \pm 67 \Omega \mathrm{cm}^{2}, 4.4 \pm 0.1 \mathrm{msec}, 3.0 \pm 0.1 \mu \mathrm{F} /$ $\mathrm{cm}^{2}$ and $0.72 \pm 0.01 \mathrm{~mm}$, respectively $(n=10)$ and those of innervated muscle fiber were $0.63 \pm 0.02 \mathrm{M} \Omega, 930 \pm 33 \Omega \mathrm{cm}^{2}, 2.3 \pm 0.1 \mathrm{msec}, 2.6 \pm 0.1 \mu \mathrm{F} / \mathrm{cm}^{2}$ and $0.59 \pm$ $0.02 \mathrm{~mm}$, respectively $(n=15)$. 
Figure 10 shows an example of current-voltage relationships recorded before and after denucleation (7 days). The denucleated muscle fiber showed a lower value of RMP and a higher membrane resistance than that of the innervated one. The innervated muscle fiber generated action potential with overshoot $(12 \pm 2 \mathrm{mV}$, $n=10$ ), but the denucleated muscle fiber generated action potential without overshoot. Hyperpolarizing current elicited anodal-break excitation in the denucleated muscle fiber, but this action was rare in innervated fiber.
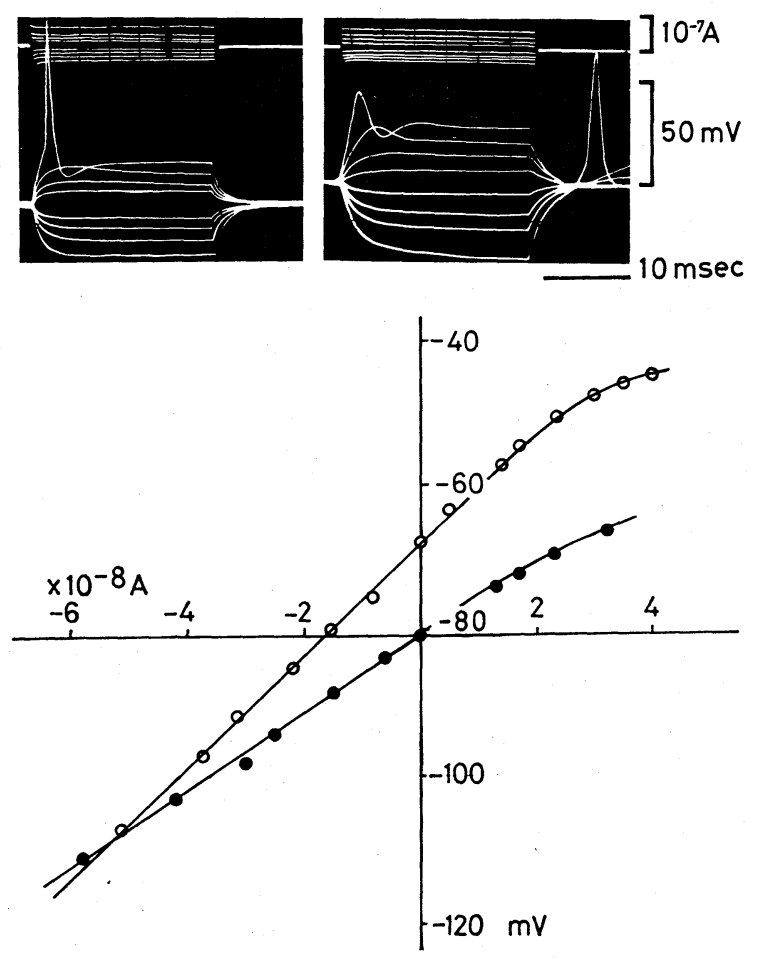

Fig. 10. Current-voltage relationships of innervated and 7 days denucleated $M$. mass. Two intracellular microelectrodes penetrated in the same fiber within the distance of $10 \mu \mathrm{m}$. Upper: left, record from innervated; right, record from denucleated $M$. mass. Lower: ordinate, membrane potential $(\mathrm{mV})$; abscissa, current $\left(\times 10^{-8} \mathrm{~A}\right)$. Closed circle, innervated; open circle, denucleated $M$. mass.

To compare the amplitude and the rate of rise of the action potential in the innervated and denucleated fiber, the RMP in the denucleated muscle fibers was displaced in a hyperpolarized direction to reach the level of the control muscle $(-81 \mathrm{mV})$. These values in denucleated muscle fiber were lower than those in innervated muscle fiber (Fig. 11). In addition, denucleation alters the physiological properties of the membrane site responsible for the generation of the action current. For example, TTX completely blocked spike generation in innervated 


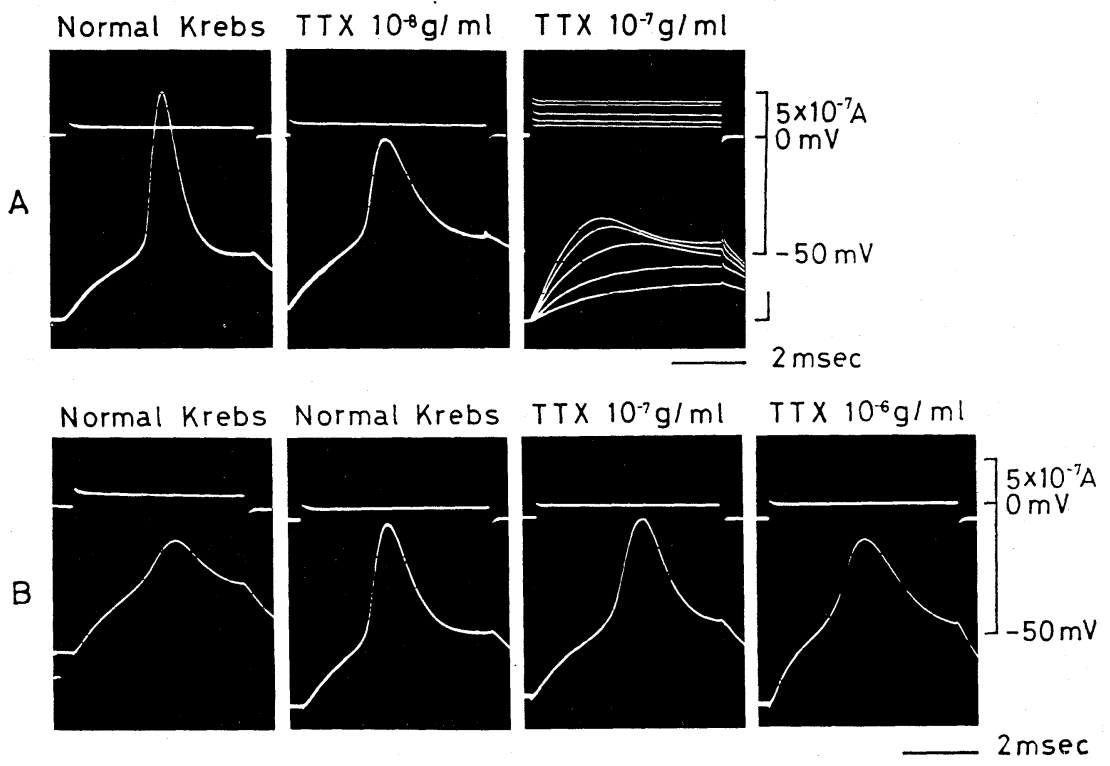

Fig. 11. Intracellular recordings of a typical action potential in innervated (A) and 10 days denucleated (B) M. mass. A : left, record obtained in abscence of TTX; right, in presence of $10^{-8}$ and $10^{-7} \mathrm{~g} / \mathrm{ml}$ TTX. B: left, two records obtained in abscence of TTX; right, in presence of $10^{-7}$ and $10^{-6} \mathrm{~g} / \mathrm{ml}$ TTX. To compare with normal innervated muscle, resting membrane potentials (lower traces), except for left one, were hyperpolarized to normal level (about $-81 \mathrm{mV}$ ) by passing current.

M. mass. at a concentration of $10^{-7} \mathrm{~g} / \mathrm{ml}$. After denucleation, however, the muscle fiber generated action potentials which were resistant to TTX as shown in Fig. 11. At a concentration of $10^{-7} \mathrm{~g} / \mathrm{ml}$ TTX the rate of rise of the action potentials in the denucleated muscle fiber (after 10 days) slightly decreased and even at high concentration of $10^{-6} \mathrm{~g} / \mathrm{ml}$ the rate of rise was reduced only to about $50 \%$ of the values obtained in the absence of this drug. The development of TTX-resistant action potentials after the denucleation coincides with the appearance of extrajunctional ACh supersensitivity which is shown in Fig. 9 right.

\section{DISCUSSION}

The results of the present experiments show that all effects of denucleation of the trigeminal motor nucleus are similar to those obtained with denervation accomplished by crushing or cutting the axon except for the longer latency of onset in denucleation. MILEDI and SLATER (1970) and many others have observed that the time of onset of degenerative changes after denervation are related to the length of the distal nerve stump. Thus, denucleation appears to be the functional equivalent of nerve crushing or cutting. 
Histochemical comparison of enzyme activity in control and denucleated masticatory muscles disclosed some different pattern of changes: oxidative enzyme (SDH) and glycolytic enzyme ( $\mathrm{PhR}$ ) substantially diminished their activity in muscle fibers of normally vigorous enzymatic activity; while changes in these enzymes were negligible or absent in muscle fibers of normally low enzymatic activity. The glycogen content showed similar reduction. These results, suggesting that these normal histochemical characteristics of muscles are no longer maintained after denervation, agree with the conclusions of others (RomANUL and HoGAN, 1965). The activity of myosin ATPase and AChE did not, however, histochemically decrease during the first 4 weeks after denucleation. Ratios of the two basic fiber types, type I (intermediate muscle fiber) and type II (red and white muscle fiber), determined by the myosin ATPase reactions, were not significantly different among the normal, control and denervated muscles. KARPATI and ENGEL (1968) reported that up to 27 weeks after denervation, histochemical typing of fiber by myosin ATPase reaction ratios probably reflected the original fiber type. RoMANUL and VAN DER MEULEN (1966) reported that cross-innervation treatment of rat was followed by reversal of myosin ATPase reaction. Furthermore, in developing muscles there was no difference between fiber types, for identical low myosin ATPase activity existed before innervation by motoneurons (GUTH and SAMAHA, 1972). These results suggest that the motoneuron is necessary for initiation but not for maintenance of histochemical myosin ATPase activity. On the other hand, GuTMANN et al. (1972) showed that biochemical myosin ATPase activity of the extenser digitorum longus muscle of adult rats decreased in the first 3-7 days after nerve section, but similar changes were negligible in the soleus muscle. SYrový et al. (1971) reported an increase of biochemical myosin ATPase activity in denervated soleus muscle of the rabbit, while KRISHNAMOORTHY et al. (1975) observed a marked decrease of biochemical myosin ATPase activity of denervated cremaster muscle in the bonnet monkey. All of these emphasize the need to consider animal species, kind of muscle, age of animal and time after denervation. In addition, different results may be obtained by the histochemical and biochemical methods. For example, GuTH et al. (1964) reported that biochemical AChE activity decreased to $50 \%$ within 1 week despite absence of any histochemical difference. But they discussed that the histochemical method demonstrated the presence of the enzyme only at the sole plate, whereas the quantitative methods revealed enzymatic activity throughout the entire muscle fiber. Therefore, it may be necessary to consider the difference between the histochemical and biochemical data.

After denucleation the usual cytochemical criteria for identifying fiber types are lost, so the width of the Z-lines became a valuable criterion for identification of fiber types. In all fiber types, size and number of mitochondria decreased, and red muscle fiber lost the characteristic subsarcolemmal aggregations of mitochondria. Longitudinal orientation of triad was also observed in denucleated muscle fibers. The present study suggested that denervated fibers were similar, 
in part, to undifferentiated fibers (GAUTHIER and DUNN, 1973). Atrophic processes occurred at a high rate in the denucleated muscle fibers after 5-7 days, which appeared to be consistent with the histochemical results of increased acid phosphatase activity, the appearance of lysosomal enzyme in electron microscopic studies, and the reduction of contractile materials. Atrophy was attributed to the progressive hydrolytic process of myofibrils caused by lysosomal enzymes, and phagocytosis by macrophages as suggested by RoMANUL and HoGAN (1965) and Pellergrino and Franzini (1963). SR exhibited swelling-like structural changes after denucleation. SRETER (1970) studied the effect of denervation on fragmented SR particularly in regard to calcium uptake, and found that both rate and total uptake of calcium decreased. These findings suggest that changes in mechanical response may be associated with structural changes of SR and changes in contractile properties. Changes in ultrastructure of nerve endings were observed from about 3 days after denucleation. The nerve terminal broke up into small fragments, and Schwann cells moved into the cleft and replaced the axons. This is in agreement with observations made by Miledi and SLATER (1970).

Following denucleation the physiological properties of mammalian skeletal muscle undergo a number of characteristic changes: cessation of m.e.p.p.; decrease of RMP; extrajunctional ACh supersensitivity; TTX-resistant action potential, and increase of membrane resistance. Decrease or subsequent cessation of spotaneous transmitter release occurred about $30 \mathrm{hr}$ after denucleation. These changes agree with those reported in denervated preparations (MILEDI and SLATER, 1970; AlbuQUeRQUe et al., 1971). Various explanations of the reduction in RMP are suggested. LOCKE and SolOMON (1967) proposed that the active transport of $\mathrm{Na}^{+}$was impaired by denervation. KLAUs et al. (1960) and Creese et al. (1968) reported that a decrease in potassium and an increase in sodium permeability accounted for the fall in RMP. An alternative hypothesis, described by ALBUQUERQUE and MCISAAC (1970), suggested that there was a decrease in internal potassium concentration due to sequestering of potassium by newly formed protein. Recently, BRAY et al. (1976) suggested that denervation blocked electrogenic activity of the $\mathrm{Na}^{+}$-pump, and dibutyryl cyclic AMP and catecholamines were able to restore this activity. Further experiments will be required to elucidate the mechanism in detail.

Extrajunctional ACh supersensitivity, TTX-resistant action potential and decrease of the rate of rise and the amplitude of action potential were observed from about 2-3 days after denervation. Following denervation specific TTX binding fell by a factor of 2.8 (ColQuHoun et al., 1974). It seems likely, therefore, that denervation causes a reduction in the number of normal TTX-sensitive sodium channels together with the appearance of TTX-resistant channels. It was suggested that a fraction of the normal channels became transformed into TTX-resistant channels. MiLEDI and POTTER (1971) reported a correlation between the appearance of binding sites for $\alpha$-bungarotoxin in the extrajunctional region and $\mathrm{ACh}$ 
supersensitivity. They suggested that this development of extrajunctional ACh receptors and the loss of TTX sensitivity might be related. CoLQuHOUN et al. (1974) also measured the change in $\alpha$-bungarotoxin binding ability after denervation in order to compare it with the change in TTX-binding ability. The results showed that the increase in the number of $\alpha$-bungarotoxin binding sites was much greater than the decrease in the number of TTX binding sites. It is unlikely, therefore, that the two mechanisms are closely related. The increase in membrane resistance after denervation may be related to a decrease in potassium conductance (ALBUQUERQUE and MCISAAC, 1970).

The factors responsible for these histochemical, cytological and physiological changes following denucleation or denervation are not yet entirely understood, but there are two major possible factors: a neurotrophic factor (MILEDI, 1960; Guth, 1968; AlbuQUERQUe et al., 1972), and a muscle activity factor (L $\phi$ MO and Rosenthal, 1972; Riley and Allin, 1973).

In conclusion, the denucleation of the trigeminal motor nucleus shows changes similar to those obtained by denervation in many muscle preparations. Muscle inactivity and the lack of neurotrophic substances normally released from nerves might cause the development of degenerative changes. The results also indicate that denucleation is a useful tool for producing denervated muscle preparations, especially when the anatomical arrangement makes it difficult to cut the nerve fiber.

The author is grateful to Prof. H. Kuriyama and Dr. Y. Ito for their valuable advices in this work. Prof. M. Ohta and Dr. A. Simpson gave their valuable comments on this manuscript.

\section{REFERENCES}

Albuquerque, E. X. and MCIsAaC, R. J. (1970) Fast and slow mammalian muscles after denervation. Exp. Neurol., 26: 183-202.

Albuquerque, E. X., SchuH, F. T., and Kauffman, F. C. (1971) Early membrane depolarization of the fast mammalian muscle after denervation. Pflügers Arch., 328: 36-50.

Albuquerque, E. X., Warnick, J. E., Tasse, J. R., and Sansone, F. M. (1972) Effects of vinblastine and colchicine on neural regulation of the fast and slow skeletal muscles of the rat. Exp. Neurol., 37: 607-634.

AXelsson, J. and THESLEFF, S. (1959). A study of supersensitivity in denervated mammalian skeletal muscle. J. Physiol., 147: 178-193.

Bray, J. J., Hawken, M. J., Hubbard, J. I., Pockett, S., and Wilson, L. (1976) The membrane potential of rat diaphragm muscle fibers and the effect of denervation. J. Physiol., 255: 651-667.

Colquhoun, D., Rang, H. P., and Ritchie, J. M. (1974) The binding of tetrodotoxin and $\alpha-$ bungarotoxin to normal and denervated mammalian muscle. J. Physiol., 240: 199-226.

Creese, R., El-Shafie, A. L., and Vrbová, G. (1968) Sodium movements in denervated muscle and the effects of antimycin A. J. Physiol., 197: 279-294.

DEL CASTillo, J. and KATz, B. (1955) On the localization of acetylcholine receptors. J. Physiol., 128: $157-181$.

Dubowitz, V. and Pearse, A. G. E. (1960) A comparative histochemical study of oxidative enzyme and phosphorylase activity in skeletal muscle. Histochemie, 2: 105-117. 
Eccles, J. C., Eccles, R. M., and KozaK, W. (1962) Further investigations on the influence of motoneurones on the speed of muscle contraction. J. Physiol., 163: 324-339.

ENGEL, W. K. (1962) The essentiality of hist- and cytochemical studies of skeletal muscles in the investigation of neuromuscular disease. Neurology (Minneapolis), 12: 778-794.

FALK, G. and FATT, P. (1964) Linear electrical properties of striated muscle fibers observed with intracellular electrode. Proc. R. Soc. London, Biol., 160: 69-123.

GAUTHER, G. F. (1969) On the relationship of ultrastructural and cytochemical features to color in mammalian skeletal muscle. Z. Zellforsch. Mikrosk. Anat., 95: 462-482.

GAuthIER, G. F. and DunN, R. A. (1973) Ultrastructural and cytochemical features of mammalian skeletal muscle fibers following denervation. J. Cell Sci., 12: 525-547.

Gomori, G. (1950) An improved histochemical technique for acid phosphatase. Stain Technol., 25: 81 .

Guth, L. (1968) 'Trophic' influences of nerve on muscle. Physiol. Rev., 48: 645-687.

Guth, L., Albers, R. W., and Brown, W. C. (1964) Quantitative changes in cholinesterase activity of denervated muscle fibers and sole plates. Exp. Neurol., 10: 236-250.

Guth, L. and SAMAHA, F. J. (1972) Erroneous interpretations which may result from application of the "myofibrillar ATPase" histochemical procedure to developing muscle. Exp. Neurol., 34: 465-475.

Gutmann, E., Melichna, J., and Syrový, I. (1972) Contraction properties and ATPase activity in fast and slow muscle of the rat during denervation. Exp. Neurol., 36: 488-497.

Hodgkin, A. L. and Rushton, A. H. (1946) The electrical constants of a crustacean nerve fiber. Proc. R. Soc. London, Biol., 133: 444-479.

Hogan, E. L., Dawson, D. M., and Romanul, F. C. (1965) Enzymatic changes in denervated muscle. II. Biochemical studies. Arch. Neurol., 13: 274-282.

KARPATI, G. and ENGel, W. K. (1968) Histochemical investigation of fiber type ratios with the myofibrillar ATPase reaction in normal and denervated skeletal muscles of guinea pig. Am. J. Anat., 122: 145-156.

Klaus, W., Lüllmann, H., and Muscholl, E. (1960) Der Kalium-Flux des normalen und denervierten Rattenzwerchfells. Pfügers Arch. Ges. Physiol., 271: 761-775.

Koelle, G. B. and Friedenwald, J. S. (1949) A histochemical method for localizing cholinesterase activity. Proc. Soc. Exp. Biol. Med., 70: 617-622.

Krishnamoorthy, R. V., Rahaman, H., and SriHARI, K. (1975) Biochemical changes in denervated cremaster muscle and its relationship to spermatogenesis in the bonnet monkey. Exp. Neurol., 46: 389-401.

KRNJEVIć, K. and Miledi, R. (1958) Failure of neuromuscular propagation in rats. J. Physiol., 140: $440-461$.

LEWIS, D. M. (1962) The effect of denervation on the speeds of contraction of striated muscle. J. Physiol., 161: 24P.

LEWIS, D. M. (1972) The effect of denervation on the mechanical and electrical responses of fast and slow mammalian twitch muscle. J. Physiol., 222: 51-75.

Locke, S. and Solomon, H. C. (1967) Relation of resting potential of rat gastrocnemius and soleus muscles to innervation, activity and the Na-K pump. J. Exp. Zool., 166: 377-386.

L $\phi$ MO, T. and RosenthaL, J. (1972) Control of ACh sensitivity by muscle activity in the rat. $J$. Physiol., 211: 493-513.

Masuda, K., TAKahashi, S., and KurIYAMA, H. (1974) Studies on the fiber types of the guinea pig masticatory muscles. Comp. Biochem. Physiol., 47: 1171-1184.

McManus, J. F. A. and Mowry, R. W. (1960) Staining Methods: Histological and Histochemical. Harper and Row, New York.

Miledi, R. (1960) The acetylcholine sensitivity of frog muscle fibers after complete or partial denervation. J. Physiol., $151: 1-23$. 
Miledi, R. and Potter, L. T. (1971) Acetylcholine receptors in muscle fibers. Nature, 233: 599-603.

MiLedi, R. and Slater, C. R. (1970) On the degeneration of rat neuromuscular junctions after nerve section. J. Physiol., 207: 507-528.

Muscatello, U. and Patriarca, P. L. (1968) Denervation and disuse atrophy in pigeon breast muscle. Am. J. Pathol., 52: 1169-1189.

Nachlas, M. M., Tsou, K. C., DeSousa, E., Cheng, C. S., and Seligman, A. M. (1957) Cytochemical demonstration of succinic dehydrogenase by use of a new $p$-nitrophenyl substituted ditetrazole. J. Histochem. Cytochem., 5: 420-436.

Padykula, H. A. and Herman, E. (1955) The specificity of the histochemical method for adenosine triphosphatase. J. Histochem. Cytochem., 3: 170-183.

Pellergrino, C. and Franzini, C. (1963) An electron microscope study of denervation atrophy in red and white skeletal muscle fibers. J. Cell Biol., 17: 327-349.

Purves, D. and Sakmann, B. (1974) The effect of contractile activity on fibrillation and extrajunctional ACh-sensitivity in rat muscle maintained in organ culture. J. Physiol., 237: 157182.

RedFERN, P. and THESLEFF, S. (1971) Action potential generation in denervated rat skeletal muscle, I. Quantitative aspects. Acta Physiol. Scand., 81: 557-564.

Riley, D. A. and Allin, E. F. (1973) The effects of inactivity, programmed stimulation and denervation on the histochemistry of skeletal muscle fiber types. Exp. Neurol., 40: 391-413.

Romanul, F. C. and Hogan, E. L. (1965) Enzymatic changes in denervated muscle. I. Histochemical studies. Arch. Neurol., 13: 263-273.

Romanul, F. C. and VAN DER Meulen, J. P. (1966) Reversal of the enzyme profiles of muscle fibers in fast and slow muscles by cross innervation. Nature, 212: 1369-1370.

SAMAHA, F. J., GUtH, L., and AlBers, R. W. (1970) The neural regulation of gene expression in the muscle cell. Exp. Neurol., 27: 276-282.

SRETER, F. A. (1970) Effect of denervation on fragmented sarcoplasmic reticulum of white and red muscle. Exp. Neurol., 29: 52-64.

Syroví, I., Gutmann, E., and Melichna, J. (1971) Differential response of myosin-ATPase activity and contraction properties of fast and slow rabbit muscles following denervation. Experientia, 27: 1426-1427.

TAKeUCHI, T. and KURIAKE, H. (1955) Histochemical detection of phosphorylase in animal tissues. J. Histochem. Cytochem., 3: 153-160.

Tower, S. S. A. (1935) Atrophy and degeneration in skeletal muscle. Am. J. Anat., 56: 1-43. 